\title{
How nurses built a specialty from scratch
}

Jenny Bryan

\section{Haemophilia nursing is a relatively young specialty. For early nurses like Maureen Fearns there was no roadmap. She recalls the birth and early tribulations of the HNA}

When Maureen Fearns became

haemophilia sister in Newcastle in 1974,

she was one of a handful of nurses in the UK specialising in treating the disorder. Until then, haemophilia care had been focused on hospital wards as most people were treated as inpatients, often for long periods. But the arrival of factor VIII and factor IX concentrates in the early 1970s meant that treatment could be given in an outpatient setting, and triggered a revolution that put nurses at the heart of the UK's haemophilia service.

"At the start, there was very little information about the kind of service a haemophilia centre should provide and, to some extent, we had to make it up as we went along. I spent a couple of weeks at the haemophilia centre in Oxford - one of only a few in the UK - to see how they were doing things, and then I set to work in Newcastle. Our centre director set up a comprehensive care team to provide holistic care for the haemophilia patient and their family," Maureen recalls.

It's hard to believe but, in the 1970s, nurses didn't take bloods, put needles in or put up drips, so there was a steep learning curve for Maureen and others at the vanguard of the new nursing specialty.

"Initially, I sent out a one page newsletter to nurses working with haemophilia patients at other centres, asking them what they were doing and how they were doing it, and whether they'd be interested in sharing information - and we just took it from there," says Maureen.

\section{First national meeting}

Companies selling commercially sourced blood products from the USA were keen to establish educational initiatives. They identified centres that had a haemophilia nurse and went on to support the first meeting of haemophilia nurses held in London in July 1976 (see panel). Among the presentations, Maureen described her experiences of setting up a home

\section{Jenny Bryan}

Email: jlrbryan@abtinternet.com treatment programme in Newcastle, which was used at that time by 50 severely affected patients with haemophilia, aged from 6 to 54 years. "We were keen to normalise life for boys and men with haemophilia and to enable them to have full time education and employment. When they had a bleed, they could now get immediate treatment at home, so they could get back to school or work, instead of being hospitalised."

\section{"At the start, there was little} information about the kind of service a haemophilia centre should provide... we had to make it up as we went along"

Further meetings followed and, in 1981, Maureen and Patricia Turk from Treloar's School and College for young people with disabilities in Alton, Hampshire, set up the Haemophilia Nurses Association (HNA), with recognition from the Haemophilia Centre Directors organisation.

The aims of the HNA included promoting improved patient care, providing training for newly appointed nurses and establishing links with organisations such as the Haemophilia Society, and the Haemophilia Chartered Physiotherapists Association.

"We wanted to produce educational tools for healthcare providers, patients and families and to monitor training for home therapy programmes. We also wanted to carry out annual surveys of treatment provision, hold meetings for members, publish an annual newsletter, and meet the requirements of the membership in all ways we could," says Maureen.

Initially, the HNA worked under the umbrella of the Haemophilia Society. During the 1980s, about 40-50

haemophilia nurses joined the HNA and, all too soon, it became a vital source of support for a profession in turmoil.

\section{The bombshell years}

The Haemophilia Society estimates that, during the 1970s and 80s, almost 5,000 people contracted hepatitis $C$ following exposure to contaminated blood products, with about 1,200 co-infected with HIV. About 2,000 people have died following exposure to hepatitis C, 840 of whom were co-infected with HIV.

Maureen explains that, during this difficult time for the haemophilia community, HNA Linkline was set up to put nurses, physiotherapists and social workers involved in haemophilia care in touch with colleagues for help and support in addressing the needs of patients and families. "In Newcastle, we had 120 severely affected haemophilia patients, and 99 were found to be HIVpositive. No one could ever have imagined what it would be like to sit down with patients and their families and tell them

\section{Maureen (left) with haemophilia colleagues at a meeting in the mid-1990s}

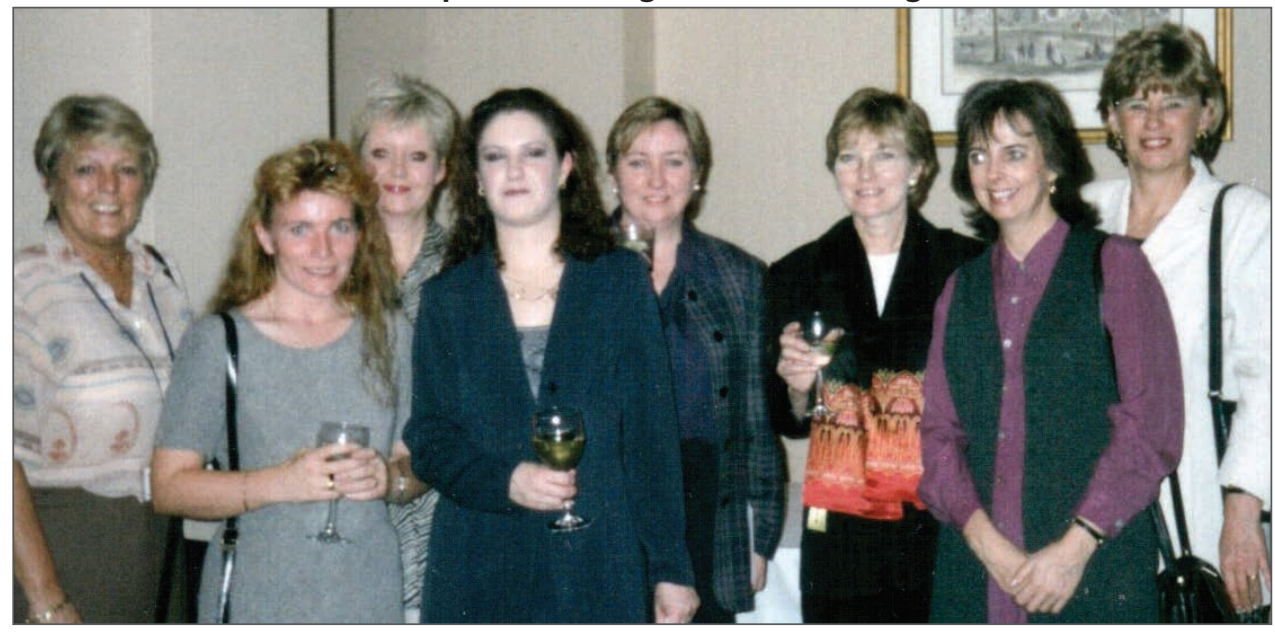




\section{Home treatment forged the nurse's role}

\section{Maureen Fearns gave the following presentation on home therapy to a nurses conference on 9 July 1976}

In most parts of the country, home therapy programmes have been set up using some type of factor VIII and on the whole doctors, nurses and patients alike feel that to date this is the most satisfactory way of helping the haemophiliac and his relatives to lead a more normal life.

I would like to give a brief outline of my responsibilities in the planning, teaching and follow-up of patients on the home therapy programme run by the Newcastle Centre.

The programme was started at the end of and to date 49 patients are receiving factor VIII concentrate at home and one patient factor IX concentrate. The age range of these patients is 6-54 years. These patients were all well known to us for many years and therefore selection to the programme was made easier.The one major restriction was financial, as a commercial concentrate was chosen for treatment and this had to be paid for from the area's budget. The reasons for choosing a commercial concentrate, namely Hemofil, were as follows:

- Ease of injection and mixing

- Known number of units per vial

- Easy storage (household fridge) and travelling

\section{- Small volume}

\section{- Reduced side effects}

When the patients attended the centre for outpatient treatment I started by giving a small amount of instruction while administering the intravenous therapy. In many cases the patients opted to insert their own needles long before training for home therapy. I think this is important so that one is not faced with the whole project to be learnt in two days.

Having been selected for the programme, the patient and his relatives attend the centre for two consecutive days. Often only mum will arrive for tuition but we do encourage father to come also. The first step is to have a full joint and muscle assessment by the physiotherapist, and usually at this point she will make arrangements for any plastic night splints or special ankle splints to be made. This gives a good baseline by which to judge treatment progress and management.

The haemophiliac and relatives then start two days of instruction:

- Signs and symptoms of each type of bleed

- When to treat a bleeding episode

- Methods of injecting

- Recording of data after treatment.

When the centre director has seen venepuncture being successfully performed the patient then mixes and injects himself with one vial to which we can monitor response. Our patients are of course encouraged to treat themselves immediately they feel a bleed start - that is normally before there are any visible signs.

\section{"Perhaps now that we are beginning to achieve a reduction in physical disability, we should begin to concentrate on helping patients with the social and psychological aspects that arise with home therapy"}

Most patients initially treat themselves with one vial of concentrate (250 units for a minor bleed and two vials for a major bleed). The dosage may be repeated after 12 hours if the bleed has not settled. For a bleed into a weightbearing joint, a third dose is given and if the bleed has not completely settled they must contact the centre for advice.

Within a short time patients are able to treat their bleeding episodes adequately and effectively. This can easily be checked by close observation of the recording book and frequent assessment by the physiotherapist.

Patients in Newcastle are issued with ten vials of concentrate to take home and work on a topping-up system as they get down to the last two. At present we insist on the patient attending himself for inhibitor screening, Australia antigens, blood count and liver function tests. Often on these occasions more time is spent talking about social problems rather than problems with treatment.

However, some problems have arisen as a result of home infusion as, I am sure many nurses will have experienced.
Initially problems usually concern venepuncture, these seem to settle within a short time as soon as the patient or his relative become more expert in the procedure and can use several veins instead of his one 'favourite'.

My second concern is lack of liaison with the patient's GP. This can lead to several problems, particularly with analgesics. Although these are normally prescribed by the centre in small amounts, patients can obtain further supplies from their GPs without our knowledge. This has led to drug dependency in one of our patients.

I feel that poor communication between hospital and family doctor contributed to this. Although on commencement of home treatment I always send a letter and information book to each patient's GP inviting them to visit us or ring the centre for discussion, there has been little response. But closer involvement with the GP may help in getting the patient away from the hospital environment.

Having given patients home therapy they are more able to cope with normal schooling and long-term employment.

If the haemophiliac is to lead a more active life in the community, how often should we as doctors and nurses expect him to return to the centre? On average our patients attend once in two months. But is it really necessary for them to return so often or should we give them more freedom by supplying them with adequate materials to last for 6 months to 1 year? There must be many thoughts on this but I feel those who need more support will attend the centre irrespective of whether they need treatment or social help.

At Newcastle we have two part-time social workers. In common with the other members of the team they are aware of the special problems associated with the disorder and are always available for consultation.

In summary, I feel from my experience that the the nurse's role in caring for haemophiliacs has changed with the advent of home treatment. Perhaps now that we are beginning to achieve a reduction in physical disability, we should begin to concentrate on helping patients with the social and psychological aspects that arise with home therapy. 
they were infected with HIV or hepatitis C. The new concentrates revolutionised the lives of people with haemophilia, helping them to be so much more independent, but they also brought our patients different diseases."

Some nurses were so distressed that they left haemophilia, but others carried on and included care of HIV and hepatitis $\mathrm{C}$ alongside haemophilia care. The HNA was there to help because members understood what everyone was going through. It set up small meetings so nurses could talk to each other about the challenges they were facing, and information was developed on how to address the additional treatment needs of patients and their families. Every three months HNA members were sent a brief update on urgent issues and events related to the crisis.

During the 1990s, when patients started to show symptoms of hepatitis C, the HNA was again involved in an educational initiative to help members learn about further needs for treatment.

\section{Training initiatives}

Continuing support from pharmaceutical sponsors enabled the HNA to offer funding to newly appointed haemophilia nurses so they could receive training for up to two weeks at established haemophilia centres. In addition to biennial national meetings, the HNA ran regional meetings where members could discuss local issues and exchange ideas about good practice. It also produced educational videos for nurses, and videos for patients, which were distributed by the Haemophilia Society.

Some 20 years after the first haemophilia nurses took up their posts, the HNA drew up a basic job description for nurses specialising in haemophilia, encompassing clinical practice, advocacy, advice, education and research [1].

A paper-based competency framework for nurses caring for people with haemophilia and related bleeding disorders was drawn up by the HNA in 2002. This was based on Benner's noviceto-expert nursing model including frames of practice in clinical skills, evidencebased care, communication, supportive care and social care [2]. An on-line version of the framework is now available on Haemnet (www. haemnet.com). The framework included extended areas of competency in paediatrics, inhibitors, women's health, genetics and leadership.
The HNA has continued to work enthusiastically to develop specialist education for nurses and physiotherapists. This resulted in the valuable Essentials of Haemophilia Care Course, which was first delivered in 2000. The course has adapted over time to meet developments in haemophilia care and nursing. Most haemophilia nurses in the UK have successfully completed it, as have some nurses from overseas and health care professionals from other disciplines such as physiotherapy and laboratory medicine.

New initiatives and developments in specialist and advancing practice have required additional educational support. The Advancing Haemophilia Care course was a natural progression and now addresses these development needs. There is now a formal and recognised academic career pathway for haemophilia nurses that enhances individual practice and ensures equity in care provision for patients.

The advent of the role of consultant nurse in haemophilia - there are now three in the UK - shows that haemophilia nursing has the potential to develop further as health care demands change, while retaining a patient focus. Key role descriptors for the consultant nurse in haemophilia include advanced practice skills and protected time for academic achievement including doctoral studies, university lectureship, running training courses and supporting nursing

development globally

Recognising the need for haemophilia nurses to work more closely with other healthcare professionals in the field, the HNA arranged for nurse representation at meetings of the UK haemophilia centre directors, and for committee members to act as links with haemophilia,

physiotherapy and social work special interest groups.

The first joint meeting of haemophilia nurses, physiotherapists and social workers took place in Birmingham in 1994 and nurses and physiotherapists have continued to give presentations at educational meetings of each other's professional organisations.

In 1999, the HNA became a specialist interest group of the Royal College of Nursing (RCN), which enabled the Association to get much-needed logistical support. An RCN link person attended HNA committee meetings, giving the Association direct access to support for projects and publications.
"The HNA stayed in charge of the structure of the organisation and all our financial sponsorship was ring-fenced, but the RCN took over much of the administration, including sourcing venues for our meetings," explains Maureen.

HNA educational meetings were incorporated into continuing education programmes and were recognised for the award of CME points by the RCN. However, affiliation with the RCN ended in 2011 when the RCN proposed merging the HNA into the IV and Haematology Nurses Forum, which it was felt would not meet the particular education and training needs of haemophilia nurses.

But the HNA is also closely involved with the World Federation of Hemophilia Nurses Committee, whose vision is to improve the quality of care to patients with haemophilia and other bleeding disorders worldwide, by enhancing nursing practices and making nursing an integral part of the multi-disciplinary health care team. Maureen joined the Committee in the late 1970s, and the UK has maintained membership, via the HNA, ever since.

\section{Changing times, changing needs}

The HNA now has an active membership of over 120 nurses who care for patients with bleeding disorders within haemophilia centres and local hospitals in either a full-time or part-time capacity.

For more than three decades, the HNA has adhered to its original goals - to improve patient care through education, training and support of haemophilia nurses. In 2013, 18 haemophilia nurses successfully completed the Essentials of Haemophilia course at diploma/degree level, and the Advanced (masters level) course was revalidated and will run at Sheffield Hallam University in 2014.

Maureen is now retired from haemophilia nursing, but still takes a keen interest in the specialty. "Year on year, there have been new challenges and new needs within the haemophilia community. The goalposts have moved and the nursing role has changed, but the HNA has evolved to keep up with the changes. For me, it has been about good education and meaningful support and, not least, great friendships."

\section{References}

1. Royal College of Nursing. Role descriptor for Clinical Nurse Specialists in haemophilia and Related

Disorders. RCN, 1994.

2. Benner P. From novice to expert. Am J Nurs 1982; 82(3): $402-7$. 


\title{
How nurses came together to form the HNA
}

\author{
The HNA was formed on 13 March \\ 1981. The following day, Maureen \\ Fearns explained why the association \\ was needed in a speech to the \\ Haemophilia Society
}

During the last 10 years the role of the nurse has expanded as legislation in the nursing profession in general has changed. In particular the haemophilia nurse has a specialized role to play as part of a team caring for haemophiliacs.

Each day we learn new things, but the knowledge required to set up and run a centre effectively must be gained from somewhere. The basic nursing skills we acquire during training would never prepare us for the job upon which we are about to embark. There are no courses available for training us, so how do we learn this new way of working? Until now most of our knowledge has been gained from the haemophiliac and his relatives and occasionally via another nurse already practising in a haemophilia centre.

The haemophilia centre director is our greatest professional source of information. However, there is often a need for more basic information.

Those of you who have haemophilia, or who are part of a patient's family or circle of friends, may possibly have the greatest understanding in a broader sense than any one individual involved in your care will ever have. However, each person in a haemophilia team has his own specialist skills, which no other member of that team could ever perform to the full.

In recent years, many associations and societies have been set up, for the patient, the doctor and the social worker. Although all of these people can help teach the nurse many aspects of care, none can teach her specific skills or define the nurse's role.
In the past the role of the nurse has evolved from those of us who take it upon ourselves to become a sister or nurse in charge of a haemophilia centre.

When you see us carry out treatment, training for home therapy etc, hopefully with great confidence, you may never realise the nervous apprehension that has often lain behind the efficient lady in a starched uniform.

Nurses are not taught about haemophilia except for very superficial lectures during nurse training. Suddenly we are faced with many new practices, which are completely foreign to our prior knowledge of this disorder.

Those of you trained in home therapy can take consolation when I liken our initial feelings to your initial fear of having to go off and do it all yourself.

To overcome this we decided that prevention would be better than cure, and positive knowledge safer than trial and error.

While we will always look to our centre directors, for instruction and information we must learn more basic things from others. This we feel will best come from those nurses already established in haemophilia centres. The difficulty is how to exchange information and gather together as a group. Hence the evolution of a Haemophilia Nurses Association, of which I will be Chairman and Trish Turk will be Secretary and Treasurer.

In 1976, 1978 and 1980 we were fortunate to be given financial support by drug companies, to hold haemophilia nurses conferences at whcih we met each other and exchanged ideas for the first time. We were given the opportunity to hear some eminent doctors speak on many aspects of haemophilia care. Although we all appreciate these symposiums, we felt there was still some missing links in the chain.
Trish Turk and myself decided that this year we must take some positive steps to form an association through which we could organise specific aspects.

We realise our good fortune in working in good centres that are well organised and offer good services and excellent medical care to the patients. As some of us have been established in our jobs for several years, we feel an obligation to pass on our knowledge to other less fortunate nurses.

How I would have welcomed the opportunity to learn from others. The logistics involved in our job alone are extremely difficult and I cringe at the thought of how naive I was when starting out.

We have written to the haemophilia centre directors and have official recognition from Professor Bloom their Chairman. The Haemophilia Society has kindly agreed to take us under their umbrella. And the drug companies have kindly offered to help us fulfil our aims, which are initially as follows:

1 To produce an annual newsletter and bibliography of up-to-date literature. 2 To hold biennial symposiums with guest speakers keeping us informed of new developments in management of haemophilia.

3 To provide a basic observation training period in an established centre for those nurses embarking upon a career as a haemophilia nurse.

4 To tie in and communicate with the International Nurses Committee which will be established this year.

Our first ideas are small but of extreme inportance, as we believe that a well informed nurse can offer much to improve the running of a centre and that will ultimately benefit the haemophiliac and his family. Eventually we hope to link with other already established societies and associations. I hope today will be the beginning of that link.

\section{The Journal of Haemophilia Practice}

\author{
An open-access journal for sharing experience \\ in the care of people with bleeding disorders \\ www.haemjournal.com
}

